\title{
Typology of sociotechnical transition pathways
}

\author{
Frank W. Geels*, Johan Schot \\ Eindhoven University of Technology, IPO 2.10, P.O. Box 513, 5600 MB Eindhoven, The Netherlands
}

Received 1 August 2003; received in revised form 1 November 2006; accepted 3 January 2007

Available online 20 February 2007

\begin{abstract}
Contributing to debates about transitions and system changes, this article has two aims. First, it uses criticisms on the multi-level perspective as stepping stones for further conceptual refinements. Second, it develops a typology of four transition pathways: transformation, reconfiguration, technological substitution, and de-alignment and re-alignment. These pathways differ in combinations of timing and nature of multi-level interactions. They are illustrated with historical examples.
\end{abstract}

(C) 2007 Elsevier B.V. All rights reserved.

Keywords: Transition pathways; Sociotechnical regime; Multi-level perspective

\section{Introduction}

Work on transitions and system changes has expanded under different terms, e.g. regime transformation (Van de Poel, 2003), technological revolutions (Perez, 2002), technological transitions (Geels, 2002), system innovation (Elzen et al., 2004; Geels, 2005a) and transition management (Rotmans et al., 2001). Authors have proposed different pathways in transition processes, often illustrated with single case studies. This article aims to make progress by developing a typology of multiple transitions pathways. To that end, we use the multi-level perspective (MLP), which understands transitions as outcomes of alignments between developments at multiple levels. The typology is based on variations of timing and nature of multi-level interactions. The second aim is to respond to criticisms on the MLP, which point to some fundamental issues.

\footnotetext{
* Corresponding author. Tel.: +31 402475414; fax: +31 402444602.

E-mail addresses: f.w.geels@tm.tue.nl (F.W. Geels), j.w.schot@tm.tue.nl (J. Schot).
}

Section 2 recapitulates the multi-level perspective and describes some criticisms. Section 3 responds to these criticisms, and provides conceptual refinements. Building on these theoretical notions, Section 4 articulates four transition pathways, illustrated with brief historical examples. Section 5 further reflects on the role of agency in these pathways. Section 6 draws conclusions and makes qualifications.

\section{The multi-level perspective on transitions and some criticisms}

The MLP distinguishes three levels of heuristic, analytical concepts (Rip and Kemp, 1998; Geels, 2002): niche-innovations, sociotechnical regimes and sociotechnical landscape. Because we define transitions as changes from one sociotechnical regime to another, this article focuses on the regime level and interactions with the other two levels.

The sociotechnical regime is an extended version of Nelson and Winter's (1982) technological regime, which referred to shared cognitive routines in an engineering community and explained patterned devel- 
opment along 'technological trajectories'. Sociologists of technology broadened this explanation, arguing that scientists, policy makers, users and special-interest groups also contribute to patterning of technological development (Bijker, 1995). The sociotechnical regime concept accommodates this broader community of social groups and their alignment of activities. Sociotechnical regimes stabilise existing trajectories in many ways: cognitive routines that blind engineers to developments outside their focus (Nelson and Winter, 1982), regulations and standards (Unruh, 2000), adaptation of lifestyles to technical systems, sunk investments in machines, infrastructures and competencies (Tushman and Anderson, 1986; Christensen, 1997).

Technological niches form the micro-level where radical novelties emerge. These novelties are initially unstable sociotechnical configurations with low performance. Hence, niches act as 'incubation rooms' protecting novelties against mainstream market selection (Schot, 1998; Kemp et al., 1998). Niche-innovations are carried and developed by small networks of dedicated actors, often outsiders or fringe actors.

The sociotechnical landscape forms an exogenous environment beyond the direct influence of niche and regime actors (macro-economics, deep cultural patterns, macro-political developments). Changes at the landscape level usually take place slowly (decades).

The multi-level perspective argues that transitions come about through interactions between processes at these three levels: (a) niche-innovations build up internal momentum, through learning processes, price/performance improvements, and support from powerful groups, (b) changes at the landscape level create pressure on the regime and (c) destabilisation of the regime creates windows of opportunity for nicheinnovations. The alignment of these processes enables the breakthrough of novelties in mainstream markets where they compete with the existing regime. Fig. 1 has become a somewhat standardised picture of this dynamic. One new addition to this figure are downward arrows towards the niche-level, indicating that perceptions of niche actors and the size of support networks are influenced by broader regime and landscape developments. The second new addition is the $Y$-axis, which will be explained in Section 3.

This conceptualisation of transitions has been constructively criticised on three general points. The first criticism concerns empirical and analytical levels. For instance, Berkhout et al. (2004, p. 54) argue that "it is unclear how these conceptual levels should be applied empirically. By this we mean that a sociotechnical regime could be defined at one of several empirical lev- els". In the electricity domain one could study a regime at the level of primary fuel (coal, oil, gas) or at the level of the entire system (production, distribution and consumption of electricity). What looks like a regime shift at one level may be viewed merely as an incremental change in inputs for a wider regime at another level.

The second criticism is the relative neglect of agency, especially in representations such as Fig. 1. For instance, Smith et al. (2005, p. 1492) argue that the MLP is "overly functionalistic. Despite the breadth of the regime concept, there is a tendency to treat regime transformation as a monolithic process, dominated by rational action and neglecting important differences in context. We also argue that existing approaches tend to be too descriptive and structural, leaving room for greater analysis of agency".

The third criticism is that the approach places too much emphasis on technological niches as the principal locus for regime change. For instance, Berkhout et al. (2004, p. 62) claim that MLP-approaches are:

"unilinear in that they tend unduly to emphasize processes of regime change which begin within niches and work up, at the expense of those which directly address the various dimensions of the sociotechnical regime or those which operate 'downwards' from general features of the sociotechnical landscape".

Section 3 responds to the first and second criticism, explicating the relationships between the three MLP-levels and agency. Section 4 responds to the third criticism, and further develops the MLP into four transition pathways, based on differences in timing and nature of multi-level interactions. Our transition pathway typology deviates from Smith et al. (2005), which we briefly present below.

Smith et al. (2005) understand regime change to be a function of two processes: (1) shifting selection pressures on the regime, (2) the coordination of resources available inside and outside the regime to adapt to these pressures. Selection pressures consist of economic pressures (competition, taxes, charges, regulations), broad political, social and economic 'landscape' developments (e.g. demographic shifts, rise of consumer culture, neoliberal model of globalisation) and pressures that "bubble up from below, from innovative niches that are not yet so established as to constitute a regime" (p. 1495). They argue that "without at least some form of internal or external pressure in the diverse senses discussed above, it is unlikely that substantive change to the developmental trajectory of the regime will result" (p. 1495). This conceptualisation of regime change is similar to the MLP. For adaptation they distinguish two dimen- 
Increasing structuration

of activities in local practices

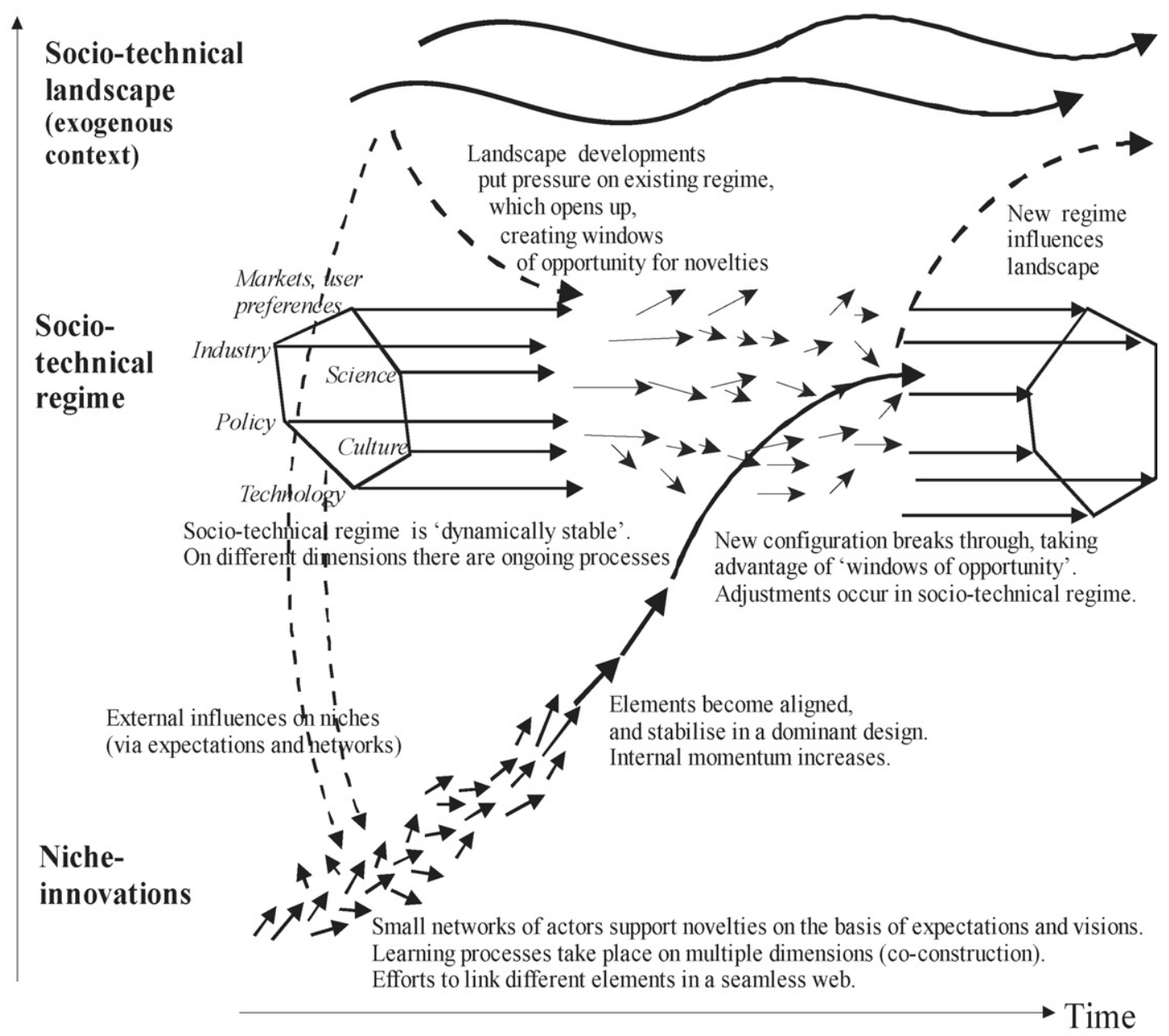

Fig. 1. Multi-level perspective on transitions (adapted from Geels, 2002, p. 1263).

sions: (a) availability of resources (factor endowments, capabilities, knowledge) and (2) degree of coordination of resource deployment. Assuming that selection pressures are always present, Berkhout et al. (2004) combine the two adaptation dimensions to construct a typology of four transitions (Fig. 2).

'Endogenous renewal' results from regime actors making conscious and planned efforts in response to perceived pressures, using regime-internal resources. 'Reorientation of trajectories' results from a shock, either inside or outside the incumbent regime, followed by a response from regime actors, using internal resources. 'Emergent transformation' arises from uncoordinated pressures, outside the regime, often driven by small and new firms. 'Purposive transitions' are intended and coordinated change processes that emerge from out-

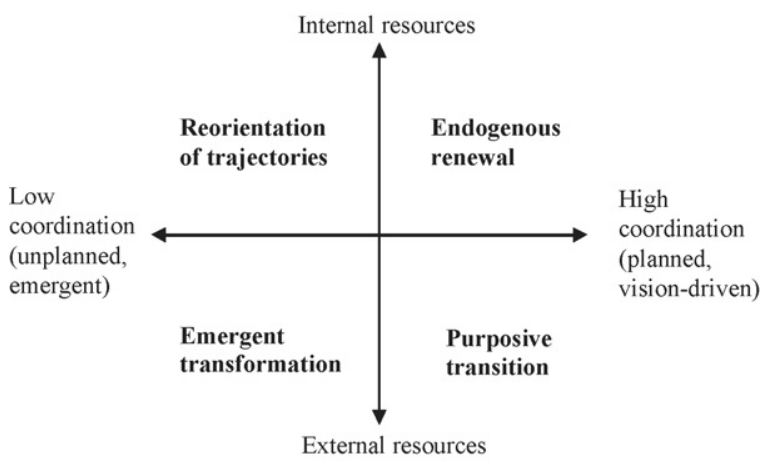

Fig. 2. Typology of transformation processes (Berkhout et al., 2004, p. 67). 
side the existing regime. Purposive transitions are seen as "deliberately intended and pursued from the outset to reflect an explicit set of societal expectations or interests" (p. 1502; our italics).

We agree with Smith et al. (2005) that a more differentiated understanding of transitions is needed. But we question their typology, especially the axis of high and low coordination, which they introduce because of their interest in governance and purposive transitions. In our view, no transition is planned and coordinated "from the outset" (p. 1502). And every transition becomes coordinated at some point through the alignment of visions and activities of different groups. This convergence is an achievement that emerges during transitions. As such, it should be investigated rather than assumed for a typology.

\section{Responses to criticisms and conceptual refinements}

\subsection{Empirical and analytical levels}

We agree that the object of analysis can be seen as nested levels. The transport system, for instance, consists of air, land and water transport systems. Land transport can be subdivided in train, tram, bus, car, bicycle systems. This can be further subdivided in local, intercity or long-distance transport. But such empirical levels are not the same as analytical levels of the MLP. The analyst should first demarcate the empirical level of the object of analysis, and then operationalise the MLP.

A complication is that there are different ways to operationalise 'levels'. Institutional theories often distinguish several organisational levels: individual, organizational subsystem, organisation, organisational population, organisational field, society, world system. Transitions in sociotechnical regimes are situated at the level of organisational fields, defined by DiMaggio and Powell (1983, p. 148) as:

"those organizations that, in the aggregate, constitute a recognized area of institutional life: key suppliers, resource and product consumers, regulatory agencies, and other organizations that produce similar services or products. The virtue of this unit of analysis is that it directs our attention not simply to competing firms (...), or to networks of organizations that actually interact, (...), but to the totality of relevant actors".

This means that we would not consider technological discontinuities that only affect one population (industry) as system innovations. In this sense, we build on Freeman and Perez (1988), who distinguish four types of innovations: incremental, radical, system, techno-economic paradigm. Radical innovations have been studied much in business studies and management, because they affect firms and industries. But system changes are more encompassing, affecting also user practices, policies, cultural meaning, etc. So the positioning of sociotechnical regime shifts at the level of organisational fields provides a lower bound of the phenomenon of transitions, distinguishing it from technological discontinuities.

\subsection{Niche-driven bias}

The criticism of bottom-up, niche-driven bias, applies mainly to early work in the strategic niche management (SNM) approach, which sometimes claimed that transitions could be brought about by nurturing niche-innovations. Later SNM-work, however, developed more nuanced policy suggestions (Hoogma et al., 2002; Raven, 2005). Furthermore, the MLP especially drew attention to broader developments to overcome the niche-driven bias: "A drawback (...) is its bias towards the novelty, and its 'innovation journey'. To counter this bias, I think more explicit attention needs to be paid to ongoing processes at the regime and landscape level" (Geels, 2002, p. 1261). So, like Smith et al. (2005), we argue that the conjuncture of multiple developments is important. But where Smith et al. aggregate different processes under the heading of 'selection pressure', we keep landscape and niche interactions as separate variables that can interact with the regime in different ways, leading to four different transition pathways (Section 4).

\subsection{Functionalism, structuralism and agency}

Because Fig. 1 does not explicitly include actors, the arrows from the niche-level may carry suggestions of teleology and functionalism. This is the danger of using figures, which always simplify to highlight particular points. To further address this criticism we will discuss the nature of the levels and their relationships to agency.

In the MLP, technological niches and sociotechnical regimes are similar kinds of structures, although different in size and stability. Both niches and regimes have the character of organisational fields (community of interacting groups). For regimes, these communities are large and stable, while for niches they are small and unstable. Both niche and regime communities share certain rules that coordinate action. For regimes these rules are stable and well articulated; for niche-innovations, they are unstable and 'in the making'. Following Scott's (1995) synthesis of institutional theory, we distinguish three 
kinds of rules ${ }^{1}$ : regulative, normative, and cognitive. Examples of regulative rules are regulations, standards, laws. Examples of normative rules are role relationships, values, behavioural norms. Examples of cognitive rules are belief systems, innovation agendas, problem definitions, guiding principles, search heuristics.

Underlying this conceptualisation is a multidimensional model of agency. We assume that actors are self-interested, act strategically, and try to calculate which actions will best achieve their goals. But cognitive capabilities and time are limited (bounded rationality). Hence, actors use cognitive rules and schemas, some of which are shared with others. Formal rules, role relationships and normative ties also enter in decisions and actions, because actors are embedded in regulatory structures and social networks. Here we follow Giddens who argues that rules are always implicated in action. In structuration theory (Giddens, 1984), rules do not exist 'out there', but only through use and reproduction in practice. Actors are embedded in rule structures, but at the same time reproduce them through their actions ('duality of structure'). Actors are not passive rule-followers ('cultural dopes'), but active rule users and makers. Actors use rules to interpret the world, make sense, and come to decisions. Rules are not just constraining (making some actions more legitimate than others), but also enabling (creating convergence of actions, predictability, trust, reliability). An important difference between niches and regimes is that the constraining influence is much stronger for the latter. ${ }^{2}$ Niche-innovations can become regimes, when social networks grow larger and rules become more stable and constraining, leading to a reversal in their relation to agency.

The sociotechnical landscape is a different kind of structure. Rip and Kemp (1998) introduced this concept in a wide-ranging review of theories of technological change. History, archaeology, anthropology and philos-

\footnotetext{
${ }^{1}$ We talk about 'rules', because the term 'institutions' is often misinterpreted as public organisations.

${ }^{2}$ Niche-innovations experience weak structuration. Social networks are small and precarious, with actors entering and leaving. Economic structures and markets are not well developed. Cognitive structures are not well articulated, indicated by disagreements about design specifications, user preferences and regulations. In sum, structures require a lot of 'work' from niche-actors to be uphold.

For sociotechnical regimes, structures are more developed and provide strong structuration, making it difficult to deviate from mainstream practice. Cognitive rules have stabilised (e.g. dominant designs). The social network is large and stable, because actors have aligned their activities. Market structures and exchange relationships have also stabilised. In sum, structuration is stronger for regimes than for nicheinnovations.
}

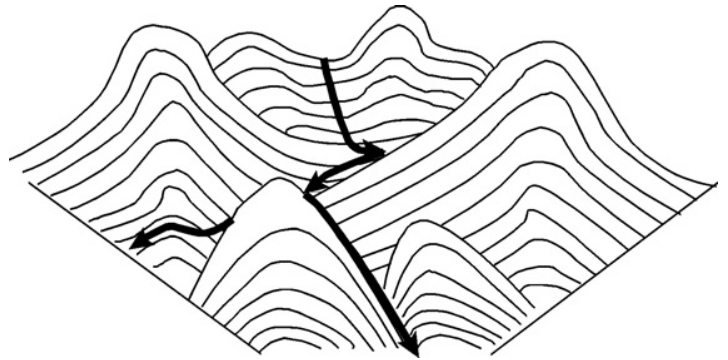

Fig. 3. Topography of development trajectories (Sahal, 1985, p. 79).

ophy view technology as part of the 'material culture' of societies. Philosophers see modern man living in a 'technotope' rather than a 'biotope'. Modern society has characteristics of a 'mega-machine' (Mumford, 1967). Historians showed how road and electricity infrastructures changed over time from strange and contested technologies to taken-for-granted backdrop. As stabilised backdrop, they still exerted power and influence. Rip and Kemp saw sociotechnical landscapes literally as something around us that we can travel through and metaphorically as something that we are part of, that sustains us (Fig. 3).

While niches and regimes work through sociological structuration, sociotechnical landscapes influence action differently. Sociotechnical landscapes do not determine, but provide deep-structural 'gradients of force' that make some actions easier than others.

We support this conceptualisation of sociotechnical landscape (which has similarities to the historian Braudel's concept of longue durée). It highlights the technical, physical and material backdrop that sustains society. However, sociotechnical landscape in this sense is relatively static, comparable to soil conditions, rivers, lakes and mountain ranges in biological evolution. But we also want to include dynamic aspects of the external environment, i.e. analogies for rainfall patterns, storms, lightning. Hence, Van Driel and Schot (2005) elaborated the landscape concept, distinguishing three types: (1) factors that do not change or that change only slowly, such as climate; (2) long-term changes, such as German industrialisation in the late 19th century; (3) rapid external shocks, such as wars or fluctuations in the price of oil. This varied set of factors can be combined in a single 'landscape' category, because they form an external context that actors cannot influence in the short run.

In this article, we propose a further differentiation, using Suarez and Oliva's (2005) article on environmental changes. Their interest is different (how firms react to major changes in business environments), but their typology is useful. They distinguish four dimensions 
Table 1

Attributes of change and resulting typology (Suarez and Oliva, 2005, p. 1022)

\begin{tabular}{lllll}
\hline Frequency & Amplitude & Speed & Scope & $\begin{array}{l}\text { Type of } \\
\text { environmental change }\end{array}$ \\
\hline Low & Low & Low & Low & Regular \\
High & Low & High & Low & Hyperturbulence \\
Low & High & High & Low & Specific shock \\
Low & High & Low & Low & Disruptive \\
Low & High & High & High & Avalanche \\
\hline
\end{tabular}

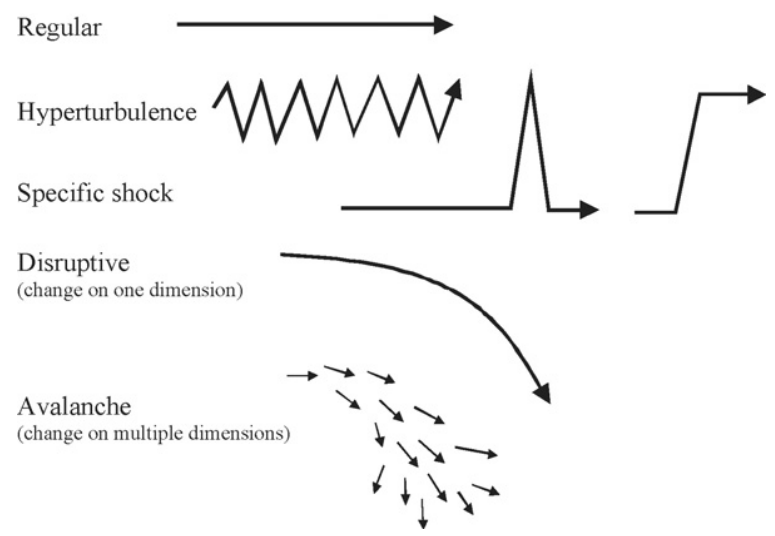

Fig. 4. Types of environmental change (based on Suarez and Oliva, 2005).

of external change: (1) frequency: number of environmental disturbances per unit of time, (2) amplitude: magnitude of deviation from initial conditions caused by a disturbance, (3) speed: rate of change of disturbance and (4) scope: number of environmental dimensions that are affected by simultaneous disturbances. They combine these four attributes into five types of environmental change (Table 1).

Regular change corresponds to environments that regularly experience a low intensity, gradual change. Hyperturbulence corresponds to environments that feature a high frequency of high-speed change in one dimension, e.g. 'hyper-competition'. Specific shock corresponds to environmental changes that are rapid and high in intensity, come rarely and are relatively narrow in scope. A specific shock may dissipate and disappear after a while, returning to base line, or it may lead to a structural stepwise change (represented with two different arrows in Fig. 4). ${ }^{3}$ Disruptive change corresponds to changes that occur infrequently, develop gradually, but have a high-intensity effect in one dimension. Avalanche change occurs very infrequently, but

\footnotetext{
${ }^{3}$ We thank one of the referees for pointing this out.
}

is of high intensity, of high speed, and simultaneously affects multiple dimensions of the environment. Avalanche change leads to permanent changes in the environment. Fig. 4 schematically gives our interpretation of these changes.

We will use this typology for our transition pathways, except for hyperturbulence. Such high-frequency changes may occur in markets, but are unlikely for landscape dynamics.

In our view, the three levels are structures that differently influence local practices where actors (inter)act. The sociotechnical landscape is a broad context that sustains action and makes some actions easier than others. These external landscape developments do not mechanically impact niches and regimes, but need to be perceived and translated by actors to exert influence (see also Smith et al., 2005). Niches and regimes, in contrast, influence action through sociological structuration. With 'action' we also mean economic and technical actions, e.g. material exchanges, R\&D investments, strategic coalitions, power struggles and competition. These actions are framed by formal, cognitive and normative rules. These semi-coherent 'rules of the game' coordinate economic and technical actions. The 'game' is serious, because it entails resources that influence life and death of firms. But the game is structured, not blind or anarchic. This does not mean that the play of games is uninteresting, that every match is the same, or that scores and performances are static. There can be a lot of economic turbulence in regimes with stable rules.

As this discussion indicates, we aim to link institutional theory, evolutionary economics, and sociology of technology (see also the quasi-evolutionary theory developed by Rip (1992) and Schot (1992)). To capture sociological and evolutionary processes in one concept, we propose the term 'socio-evolutionary'. Sociological structuration and economic action are both present in organisational fields (niches, regimes). This means there are two kinds of endogenous processes of rule changes: (1) evolutionary-economic, where rules change indirectly through market selection of product variations and (2) social-institutional, where actors directly negotiate about rules in communities.

The evolutionary-economic process is driven by organisational variety. While certain rules are shared at the field level, there is also variety because technologydevelopment actors (firms, researchers) differ in strategic choices, investment patterns, core competencies, etc. These technology-development actors compete in a selection environment (users, special-interest groups, policy agencies). A mutation can occur in the local rules and routines of a firm, leading to a somewhat different 
product. If this product has a better fit with the selection environment, the firm receives more resources and can reproduce the mutated routine. Through differential growth of the firm, the mutated routine can spread and become more dominant at the field level. Another mechanism is imitation, i.e. other technology actors copy the mutation from the successful firm. These are two evolutionary mechanisms for changes in regime rules (Nelson and Winter, 1982). The accumulation of mutations leads to technological trajectories. As long as the selection environment is stable, these trajectories advance in predictable directions.

The second dynamic is social-institutional, with social groups acting directly upon rules. Sociologists of technology conceptualise technological change as a process of sensemaking. When new technologies emerge, there is 'interpretative flexibility' (Bijker, 1995): social groups have different problem definitions and interpretations, leading them to explore different solutions. This variety of meanings is eventually reduced through 'closure', an inter-group process of negotiations and coalition building. Closure means that one interpretation eventually becomes dominant in a community and others cease to exist. This involves the build-up of a shared cognitive frame, which includes elements such as "goals, key problems, problem-solving strategies (heuristics), requirements to be met by problem solutions, current theories, tacit knowledge, testing procedures, and design methods and criteria" (Bijker, 1995, p. 123). In this socio-cognitive institutionalisation process actors directly negotiate about rules (belief systems, interpretations, guiding principles, regulations, roles). This dynamic is played out at conferences, in journals, at workshops, struggles for research grants, etc. "Researchers with different beliefs attempt to sway each other with respect to the routines utilised to judge the technology. It is in this sense that technological systems are negotiated. Therefore, competition between different paths occurs not only in the market, but also in the institutional environment" (Garud and Rappa, 1994, p. 347). Collective-action groups are often important in socio-institutional dynamics, e.g. social movements, special-interest groups, professional associations, branch organisations.

Evolutionary-economic and social-institutional dynamics are simultaneously present in organisational fields. The above conceptualisation of the three levels makes clear that actors are implicated in the MLP. This is also visible in elaborate case studies, where actors try to make sense, change perceptions as they go along, engage in power struggles, lobby for favourable regulations, and compete in markets. Hence, we disagree with
Smith et al. (2005, p. 1492) that the MLP is "overly functionalistic" and "dominated by rational action".

\section{Typology of transition pathways}

To counter a presumed, bottom-up, niche-driven bias in the understanding of transitions and to further refine the MLP, this section develops a typology of transition pathways based on different multi-level interactions. To overcome the dominance of Fig. 1 (which may suggest a bottom-up movement), this section also develops new figures for these pathways. The descriptions of transition pathways use the evolutionary and social-institutional aspects, as well as Suarez and Oliva's typology for landscape change.

To distinguish transition pathways we combine two criteria.

\subsection{Timing of interactions}

Previous MLP-publications emphasised simultaneous alignments of developments between different levels. We now add that different timings of multi-level interactions have different outcomes. Particularly important is the timing of landscape pressure on regimes with regard to the state of niche-developments. If landscape pressure occurs at a time when niche-innovations are not yet fully developed, the transition path will be different than when they are fully developed.

Whether or not niche-innovations are 'fully developed' is not entirely objective. Niche actors may have somewhat different perceptions than regime-actors. ${ }^{4}$ Nevertheless, we propose the following proxies as reasonable indicators for the stabilisation of viable niche-innovations that are ready to break through more widely: (a) learning processes have stabilised in a dominant design, (b) powerful actors have joined the support network, (c) price/performance improvements have improved and there are strong expectations of further improvement (e.g. learning curves) and (d) the innovation is used in market niches, which cumulatively amount to more than $5 \%$ market share. ${ }^{5}$

Novelty is always present, but this may be 'hidden novelty' (a term from Arie Rip), carried by relative outsiders, fringe actors or enthusiasts invisible for the

\footnotetext{
${ }^{4}$ We thank one of the referees for this observation.

5 The first three indicators stem from the literature on niche development, which emphasises three main processes: learning, network building, articulation of expectations (Kemp et al., 1998; Hoogma et al., 2002). The fourth indicator comes from diffusion research, which estimates that the diffusion curve may become self-sustaining and take off between 5 and $20 \%$ of cumulative adoption (Rogers, 1996, p. 360).
} 
outside world. Niche-innovations in an embryonic state do not pose a threat to the regime. At some moment, external landscape developments may create pressure on the regime and create windows of opportunity for transitions. But if niche-innovations are not fully developed, they cannot take advantage of this window, which may subsequently close.

\subsection{Nature of interaction}

Do niche-innovations and landscape developments have reinforcing relationships with the regime or disruptive relationships through pressure or competition?

Reinforcing landscape developments have stabilising effects on the regime and form no driver for transitions. Disruptive landscape developments exert pressure on the regime, creating impulses for change (see Suarez and Oliva's typology).

Niche-innovations have a competitive relationship with the existing regime, when they aim to replace it. Niche-innovations have symbiotic relationships if they can be adopted as competence-enhancing add-on in the existing regime to solve problems and improve performance.

Using combinations of these two criteria, we develop propositions about four different transition pathways: transformation, reconfiguration, technological substitution, and de-alignment and re-alignment. An additional fifth proposition addresses a possible sequence of transition paths, i.e. how transitions may start with one path, but shift to others. We begin with a 'zero proposition' about stability and reproduction.

P0. Reproduction process: If there is no external landscape pressure ('regular change' in Suarez and Oliva's typology), then the regime remains dynamically stable and will reproduce itself.

Radical niche-innovations may be present, but have little chance to break through as long as the regime is dynamically stable. Reinforcing landscape developments help stabilise the regime. There may be internal regime problems, but the shared perception is that the regime has sufficient problem-solving potential to deal with them.

Stable regimes still experience dynamics: firms compete in markets, invest in new product development, pioneer mutations, engage in take-overs, etc. But these processes take place within stable rule-sets and proceed in predictable directions (trajectories). Over time, accumulated incremental innovations in stable regimes can boost performance.
"A large portion of the total growth in productivity takes the form of a slow and often invisible accretion of individually small improvements in innovations. (...) Such modifications are achieved by unspectacular design and engineering activities, but they constitute the substance of much productivity improvement and increased consumer well-being in industrial economies" (Rosenberg, 1982, p. 62).

P1. Transformation path: If there is moderate landscape pressure ('disruptive change') at a moment when niche-innovations have not yet been sufficiently developed, then regime actors will respond by modifying the direction of development paths and innovation activities.

In this pathway moderate landscape changes create pressure on the regime, leading to reorientations by regime actors. Moderate landscape pressure occurs early in disruptive landscape change. ${ }^{6}$ Niche-innovations cannot take advantage of landscape pressure on the regime, because they are not sufficiently developed.

Landscape changes only exert pressure if they are perceived and acted upon by regime actors. Outsiders are important in this respect, because they translate landscape pressures and draw attention to negative externalities, which regime insiders tend to neglect (Van de Poel, 2000, 2003). Societal pressure groups and social movements may voice protest and demand solutions. They can mobilise public opinion and lobby for tougher regulations. Outside professional scientists or engineers may have specialist knowledge that allows them to criticise technical details of regimes and propose alternative courses of action. Outsider firms, entrepreneurs or activists may develop alternative practices or technologies. The demonstration of viable alternatives may change perceptions of regime insiders and lead to reorientations of (innovation) activities. Smith (2006) demonstrated this dynamic for organic food, which was initially pioneered by dedicated green activists in secluded niches. In the 1990s lessons and practices from these organic food niches were translated and picked up by regime actors (especially supermarkets). Niche actors thus acted as front-runners, whose routines and practices gradually trickled down and changed regime rules. Dedicated translation activities are important in such niche-regime interactions.

Landscape pressure and outside criticisms do not immediately lead regime actors to change their activities

\footnotetext{
6 The speed of Suarez and Oliva's 'disruptive change' is low. Hence, initial changes are small, and appear as moderate.
} 


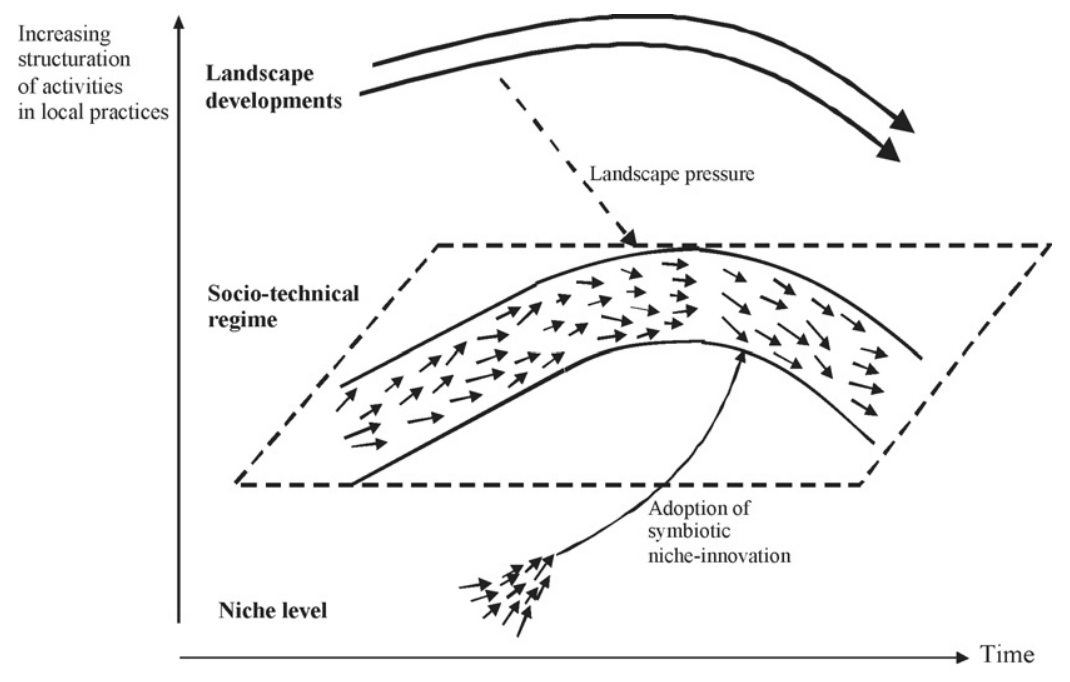

Fig. 5. Transformation pathway.

and rules. This usually involves conflicts, contestations, power struggles or dedicated translations. Socialinstitutional dynamics are important in this pathway, with social groups acting to change regime rules directly. But evolutionary dynamics are also present. In response to changes in the selection environment (societal protest, public opinion, stricter regulations), regime actors use their adaptive capacity to reorient development trajectories. Technical variations appear, some of which have a better fit with the changed selection environment. When these mutations propagate, they change the regime from within. Social-institutional and evolutionary changes thus reinforce each other.

In this path, new regimes grow out of old regimes through cumulative adjustments and reorientations (Fig. 5). Regime actors survive, although some changes may occur in social networks. Furthermore, regime actors may import external knowledge if the 'distance' with regime knowledge is not too large. Such symbiotic niche-innovations add to the regime and do not disrupt the basic architecture.

An example is the Dutch hygienic transition from cesspools to sewer systems (Geels, 2006a). Regime insiders were city governments, city councils and Departments of Public Works. Outside criticism first came from hygienist doctors, who in the 1850s found statistical correlations between infectious diseases and filthy environmental conditions, resulting from overflowing cesspools and waste-dumping on streets and in canals. They criticised regime actors and demanded better options to deal with human excrements. But regime actors downplayed the problems and took little action. Health was seen as an individual responsibility, and city authorities wanted to limit involvement in public life to keep taxes low for the middle classes that had the right to vote (about $15 \%$ of population). Regime actors only implemented incremental changes, e.g. dredging canals to improve water circulation, using steam engines to pump fresh water into canals.

In the 1870 s and 1880 s urban waste-disposal problems exacerbated, because of landscape developments. Industrialisation, for instance, drew more workers to cities, who lived in filthy slums without sanitary facilities. Hygienist doctors increased pressure on the regime. Pasteur's micro-organisms theory provided a causal explanation of the spread of infectious disease. This stimulated the emergence of a hygiene movement that emphasised the importance of cleanliness. Hygienist doctors linked up with engineers (who could develop alternative technical designs) to form a coalition of sanitary reform. In response to increased pressures, city governments somewhat altered their goals, strategies and activities. Several cities implemented dry-collection systems for the removal of human excrements. In one system people deposited excrements in barrels, which were collected several times a week. In another, pneumatic system, people used privies. Steam pumps were used to create a vacuum in underground funnels to collect excrements in a central reservoir. Both systems aimed to remove faeces and earn money by selling processed excrements as fertilizer. The scale of implementation was too small, however, to solve hygiene problems.

In the 1890s, perceptions, belief systems, norms and goals further changed. Cleanliness became a widespread cultural value as the hygiene movement gathered pace. Urbanites no longer saw filth as a nuisance to be tol- 
erated, but as moral stain on civilisation and as health danger. A new civic spirit emerged that called for more active involvement from public authorities. More active governance was also stimulated by democratisation, which created incentives for city authorities to pay more attention to working class living conditions. Hence, city governments implemented more encompassing health and hygiene solutions. Sewer systems were implemented in The Hague in 1893 with Amsterdam following in 1914.

This example followed a transformation path with gradual adjustments in regime rules, such as perceptions of disease and waste, roles of public authorities, ideology of cleanliness and waste-disposal practices. Landscape developments and struggles between regime actors and outsiders were important to bring about these changes. The example also has some aspects of substitution, because sewer systems replaced cesspools. But sewer systems were technically not disruptive. Knowledge of bricks, pipes, water flows and pumps already existed. Some additional knowledge had to be developed (about the shape of sewer pipes, sewer slopes, flow speeds, soil conditions). But this new knowledge was more an add-on to existing knowledge than a disruption. Hence, the example is closer to transformation with symbiotic niche-innovations than to technological substitution (P3).

P2. De-alignment and re-alignment path: If landscape change is divergent, large and sudden ('avalanche change'), then increasing regime problems may cause regime actors to lose faith. This leads to de-alignment and erosion of the regime. If niche-innovations are not sufficiently developed, then there is no clear substitute. This creates space for the emergence of multiple nicheinnovations that co-exist and compete for attention and resources. Eventually, one niche-innovation becomes dominant, forming the core for re-alignment of a new regime.

In this transition pathway the regime comes rapidly under much landscape pressure. Especially 'avalanche change' which divergent landscape developments may 'pull the regime apart'. The regime experiences major internal problems, collapses, erodes and de-aligns. Incumbents lose faith in the potential of the regime to respond. They do not defend the regime, signalled by declining $R \& D$ investments. The destabilisation of regime rules creates uncertainty about dimensions on which to optimise innovation efforts (guiding principles, user preferences, selection criteria, regulations, etc.). Metaphorically, the 'hollowing out' of the regime leads to a 'vacuum'.
But in this path, there is no stable niche-innovation present that can 'fill the gap'. Instead, the 'vacuum' leads to the emergence of multiple embryonic nicheinnovations, ${ }^{7}$ carried by outsiders or diversifying regime actors. The lack of stable rules leads to the exploration of multiple directions and innovation trajectories. The co-existence of multiple niche-innovations creates additional uncertainty, because product champions make competing claims. So, broad co-evolution processes precede or occur in tandem with technological changes. There is a prolonged period of co-existence, uncertainty, experimentation and competition for attention and resources. Eventually, one niche-innovation gains momentum and becomes dominant, followed by re-alignment and re-institutionalisation in a new sociotechnical regime (Fig. 6).

An example is the American transition from horsedrawn carriages to automobiles (Geels, 2005b). America in the late 19th century was a society in flux, with major political, social and cultural changes: urbanisation, immigration, hygiene movement, electricity as pervasive technology, political reform movements, expanding middle classes with more money and free time, and new values such as excitement, fun and active sporting.

These 'avalanche changes' created many problems in the existing horse-based urban transport regime: (a) the hygiene movement heightened concerns about horse excrements on streets, (b) urban expansion led to longer travel distances, which were hard to meet with horsebased transportation and (c) horse-tram companies, who operated stables with thousands of horses, complained about high cost.

The landscape changes also created opportunities for niche-innovations. Electric trams benefited from general enthusiasm about electricity, and support from powerful actors (utilities). Electric trams were also supported by incumbent horse-tram companies, an indication of regime discontent. As a result, electric trams diffused rapidly. ${ }^{8}$ Bicycles and automobiles were other popular niche-innovations. The safety-bicycle (1885), based on two wheels of the same size, was widely used for touring in the countryside, linking up with macro-values such as recreation, health and fun. Automobiles in the 1890s gained a foothold in small, but visible niches.

\footnotetext{
${ }^{7}$ In biological evolution, this pattern happened at the end of the Mesozoic era. Dinosaurs, the dominant species, disappeared following a comet impact. Mammal species, which already existed in small biological niches, took advantage of the opportunities, and quickly radiated to fill the major vertebrate positions in the ecosystems.

${ }^{8}$ In $1890,16 \%$ of American street railways were electrified, $70 \%$ were horse-powered and $14 \%$ were steam-powered. By 1902, $97 \%$ of American street railways were electric.
} 


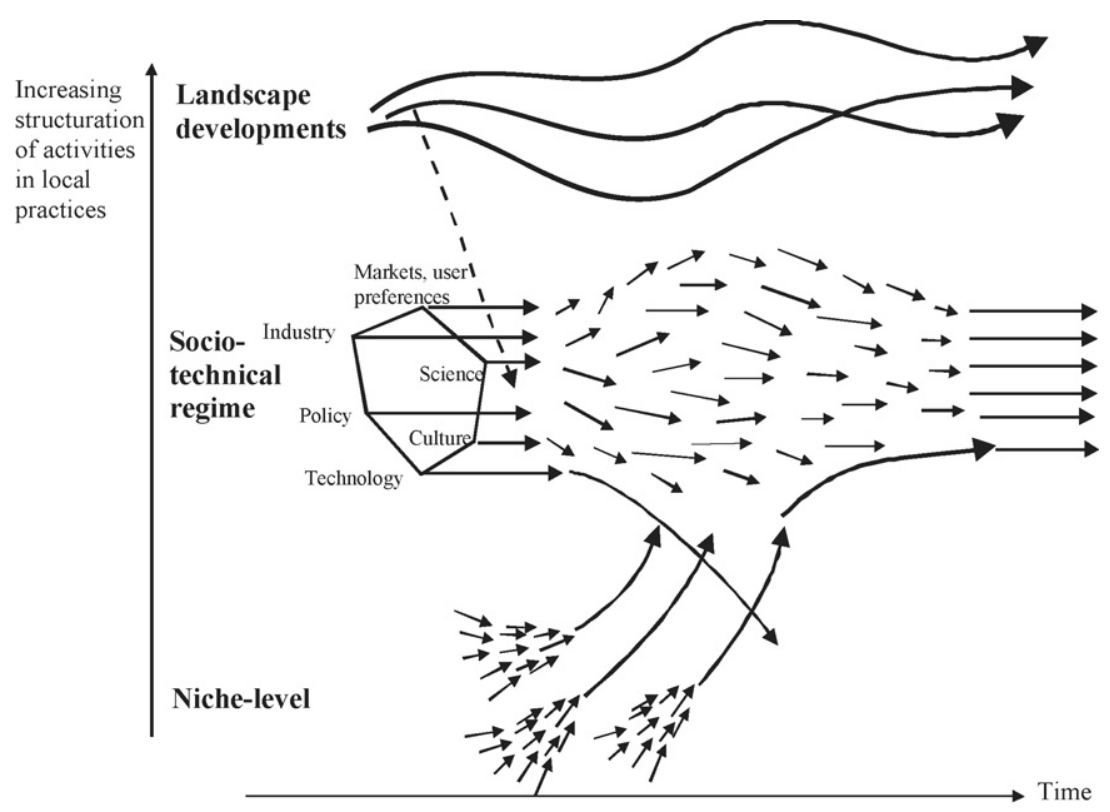

Fig. 6. De-alignment and re-alignment pathway.

Electric vehicles were used in the taxi-niche and luxuryniche (for promenading in parks and on boulevards). Gasoline cars were used in the racing-niche and the touring-niche, both popular applications that linked up with macro-values. Steam automobiles were used mainly by enthusiasts, but had less clear applications. Gasoline cars raced ahead (Table 2), especially because of the popularity of touring.

The T-Ford (1908) established a dominant design, providing clear directions for further improvement and process innovations. Ford's mass production system enabled price decreases (from $\$ 850$ in 1908 to $\$ 360$ in 1916), which stimulated diffusion. The 1920s saw increasing competition between electric trams and automobiles. For political, economic, cultural and infrastructural reasons, tram ridership began to decline in the mid-1920s, while cars further diffused, supported by a powerful road lobby. The car became strongly embedded in society, supported by new institutions such as fast food restaurants, shopping malls on the edge of cities, drive-in movies.

Table 2

Annual car sales in the United States

\begin{tabular}{lcr}
\hline & 1900 & \multicolumn{1}{c}{1905} \\
\hline Electrics & 1.575 & 1.425 \\
Steamers & 1.681 & 1.568 \\
Gasoline & 0.936 & 18.699 \\
Total & 4.192 & 21.692 \\
\hline
\end{tabular}

This example shows de-alignment of the horse-based transport regime, because of many landscape development and internal problems. Multiple novelties emerged and co-existed in the 1890s. But the example deviates from the predicted pathway, because one of the novelties, the electric tram, rapidly became dominant. It did not maintain this position, however, because it was eventually replaced by another novelty, the automobile. So this transition is a mix of de-alignment and re-alignment and two subsequent technological substitutions.

P3. Technological substitution: If there is much landscape pressure ('specific shock', 'avalanche change', 'disruptive change') at a moment when nicheinnovations have developed sufficiently, the latter will break through and replace the existing regime.

This pathway assumes that radical innovations have developed in niches, but remain stuck because the regime is stable and entrenched. ${ }^{9}$ There may be minor problems, but regime actors think these can be solved with incremental innovations. Hence, regime actors pay little attention to niche-innovations, developed by outsiders and fringe actors.

Without landscape pressure, this remains a reproduction process. It becomes a technological substitution path when a 'specific shock' (represented in Fig. 8),

\footnotetext{
9 This differs from the de-alignment and re-alignment path, where the regime destabilised early in the process.
} 


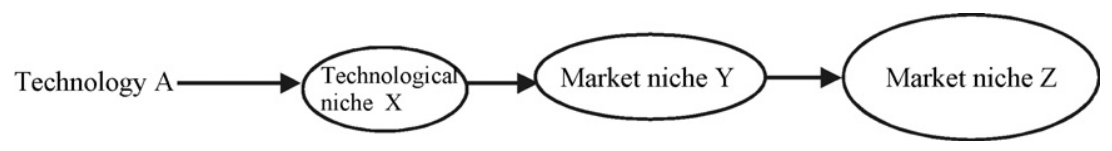

Fig. 7. Trajectory of niche-accumulation (Levinthal, 1998).

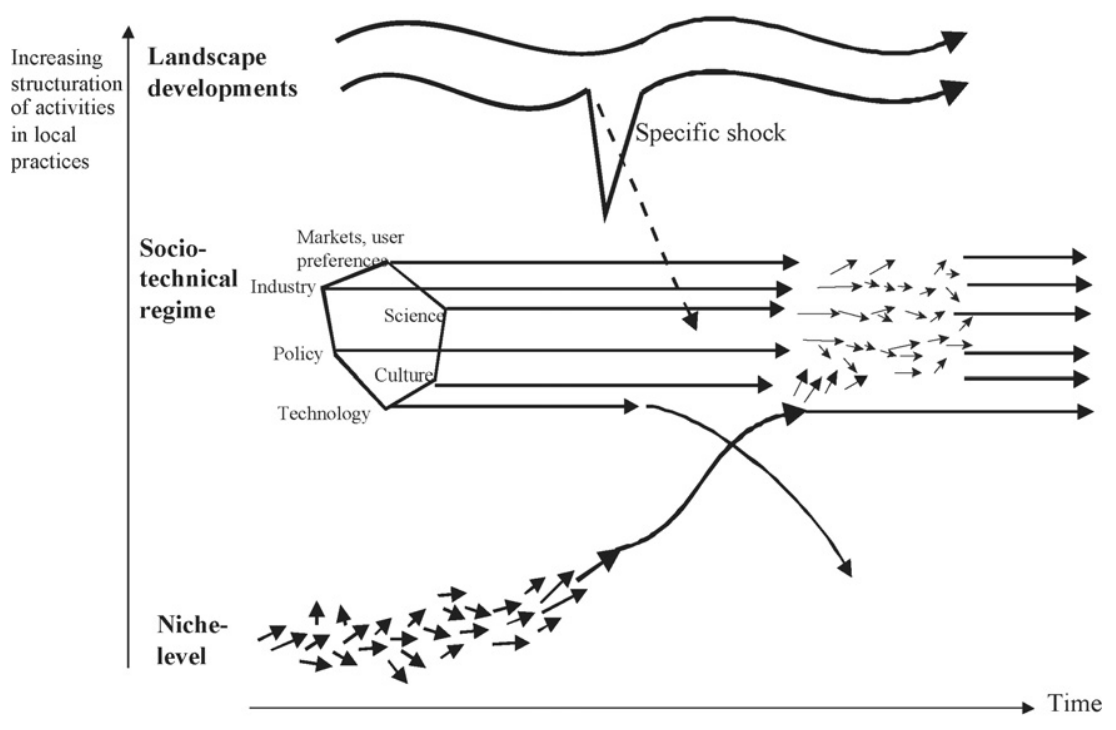

Fig. 8. Technological substitution pathway.

'avalanche change' or 'disruptive change' exerts much landscape pressure on the regime. This pressure leads to major regime tensions, and windows of opportunity for niche-innovations. Niche-innovations can use these windows, because they have stabilised and gathered internal momentum (this is another difference with the de-alignment and re-alignment path). Diffusion usually takes the form of 'niche-accumulation', with innovations entering increasingly bigger markets (Fig. 7).

When the innovation enters mainstream markets, regime actors will defend themselves and invest in improvements (the 'sailing ship effect'). ${ }^{10}$ Market competition and power struggles influence the fight between incumbents and newcomers. If the innovation replaces the old technology, this leads to knock-on effects and wider regime changes. Hence, this pathway has a technology-push character, where wider co-evolution processes follow substitution (Fig. 8). ${ }^{11}$ Because this pathway often leads to the downfall of incumbent firms,

\footnotetext{
$\overline{10}$ This is another difference with de-alignment and re-alignment, where regime actors lose faith and hardly invest in defence.

11 The outcome of this pathway is similar to P2 (de-alignment and re-alignment). In both pathways the initial regime disappears and is eventually replaced by another sociotechnical regime, based on different technologies and basic knowledge. But the process (sequence of events) leading to this outcome, is very different for both pathways.
}

it has been studied much in business studies and technology management (Tushman and Anderson, 1986; Christensen, 1997).

An example is the British transition from sailing ships to steamships (Fig. 9) (Geels, 2002).

The sailing ship regime was stable and innovative in the 1850s and 1860s, pioneering large and fast clipper ships. Steamships already existed, but were confined to small niches (inland waterways, steam tugs in ports to manoeuvre large sailing ships). In 1838 the British government created a subsidised market niche for mail steamers, to improve communication within the Empire. Although more expensive, steamships were faster and had reliable arrival times. This subsidised market provided space for the emergence of a dedicated community

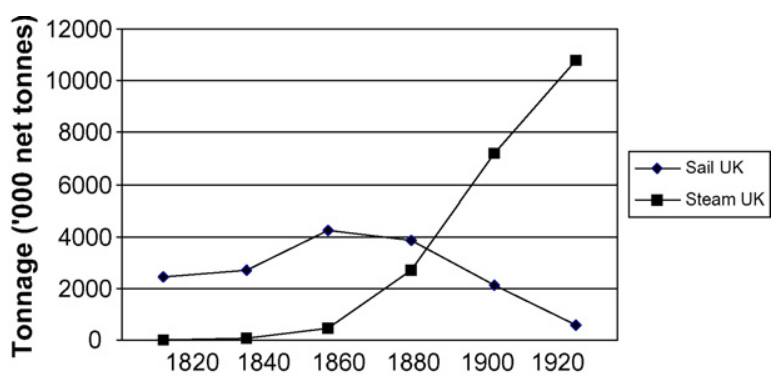

Fig. 9. Tonnage of steamships and sailing ships in Britain. 
of steamship builders, with new competencies in steam technology and iron working.

Political revolutions (1848) and the Irish potato famine (1845-1849) formed landscape changes ('specific shocks') that led to mass emigration from Europe to America, which boosted the trans-Atlantic passenger market in the late 1840 s and continuing decades. Steamships could take advantage of this window of opportunity, because technical innovations had improved performance: (a) screw propellers replaced paddle wheels, (b) coal efficiency was improved with heavier steam engines and (c) shift to iron hulls, which were capable of carrying heavier steam engines and allowed the building of bigger ships.

Diffusion accelerated when steamships entered oceanic freight trade. The opening of the Suez Canal (1869) was a crucial stimulus, because it gave steamships a major distance advantage in the India and China trades (sailing ships could not use the Canal and had to go around Africa). Also transport costs declined, because of higher coal efficiency and the building of larger ships with economies of scale. Hence, steamships replaced sailing ships between 1870 and 1890 through economic competition. This was accompanied by broader changes in the sociotechnical regime (enlarging of ports to accommodate bigger ships, creation of a world-wide coal infrastructure, new machines for loading and unloading in ports, transformation of shipbuilding yards). Incumbent sailing ships manufacturers were unable to make the shift to iron and steam. Nevertheless, for a while they defended themselves by introducing more masts and sails to increase speed, and building larger ships to increase cargo capacity.

In this example, new technologies emerged in small niches (inland waterways, ports, mail transport) while the regime was relatively stable. Technological substitution occurred, because of price/performance improvements and major landscape changes (mass emigration, Suez Canal). The transition had a technology-push character, because many adjustments in the sociotechnical regime followed the breakthrough of steamships.

P4. Reconfiguration pathway: Symbiotic innovations, which developed in niches, are initially adopted in the regime to solve local problems. They subsequently trigger further adjustments in the basic architecture of the regime.

Radical innovations are initially developed in niches. If they have symbiotic relations with the regime, they can be easily adopted as add-on or component replacement. These adoptions are driven by economic considerations (improve performance, solve small problems), leaving most regime rules unchanged. When the basic architecture remains the same, this is a transformation pathway (P1). But the adopted novelties may lead to further adjustments as regime actors explore new combinations between old and new elements and learn more about the novelties. This may lead to technical changes or changes in user practices, perceptions, and search heuristics. This may create space for new adoptions of niche-innovations. Sequences of component innovations can thus, over time and under influence of landscape pressures, add up to major reconfigurations and regime changes (Fig. 10). ${ }^{12}$

In the reconfiguration pathway the new regime grows out of the old regime (similar to transformation path P1). The difference with P1 is that the reconfiguration path experiences substantial changes in the regime's basic architecture. The reconfiguration pathway is especially relevant for distributed sociotechnical systems that function through the interplay of multiple technologies (agriculture, hospitals, retailing). In these distributed systems, transitions are not caused by the breakthrough of one technology, but by sequences of multiple component-innovations. While regime actors survive in the reconfiguration path, competition and tensions occur among component suppliers.

An example is the American transition from traditional factories to mass production (Geels, 2006b). Factory production is a complex, distributed sociotechnical regime, with many technical and social elements (Fig. 11). Sequences of smaller and larger component changes led to architectural reconfiguration that culminated in mass production.

One cluster of processes was division of labour, mechanisation, and the application of machine tools. This cluster gathered speed in the 1850 s and 1860s with the emergence of general-purpose machine tools (turret lathes, planers, boring machines, milling machines). These machine tools were operated by semi- and unskilled labourers performing limited tasks. Line shafts mechanically distributed power from steam engines to machines via by belts and pulleys (direct-drive system). Problems in this arrangement were energy loss from friction and inflexibility, because machines were fixed to the line shafts.

In the 1860 s and 1870 s, processing industries (canning, meat packing, steel making) experimented with

\footnotetext{
$\overline{12}$ Henderson and Clark (1990) developed similar ideas about architectural innovation and reconfiguration at the product level (see also the literature on modular innovation).
} 


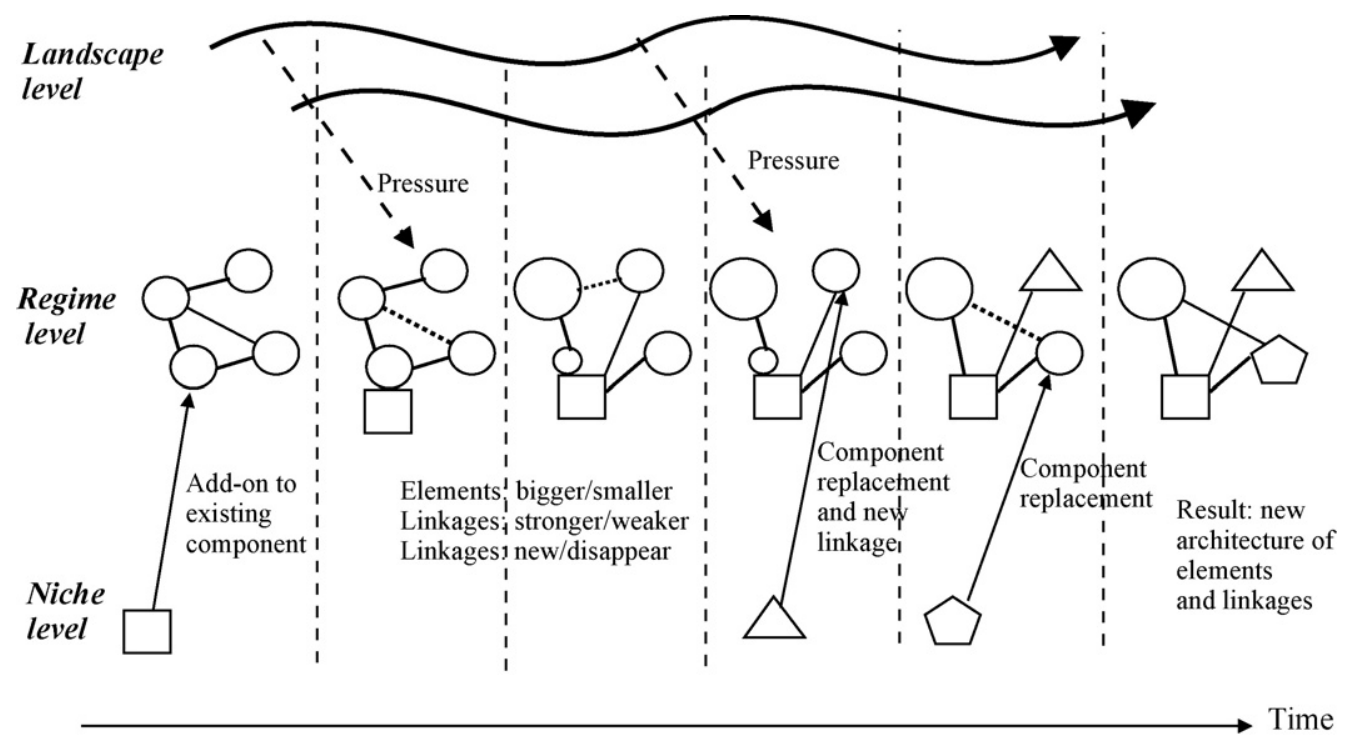

Fig. 10. Reconfiguration pathway.

continuous movement in materials handling (overhead conveyors, endless chains, moving benches). Another niche-innovation of the 1870 s were small, battery-driven electric motors, used for light power-usages such as operating dentists' drills, jewellers' lathes and small fans.

The 1880s and 1890s saw the development of specialpurpose machine tools which facilitated the production of precise, interchangeable parts. This, in turn, speeded up assembly (in the bicycle and sewing machine industry). Another development was the rise of big business in industries such as chemicals, petroleum, rubber, elec- trical equipment, steel, transportation equipment. The expanding scale and proliferation of machine tools intensified problems factory regime: (a) the direct-drive system was inflexible and constrained the size and layout of factories; inflexibility became more problematic as machine tools proliferated and (b) manual materials handling was also problematic, as more components had to be carried between the increasing number of machine tools and workstations.

Previously developed niche-innovations now entered the regime. Continuous materials handling techniques

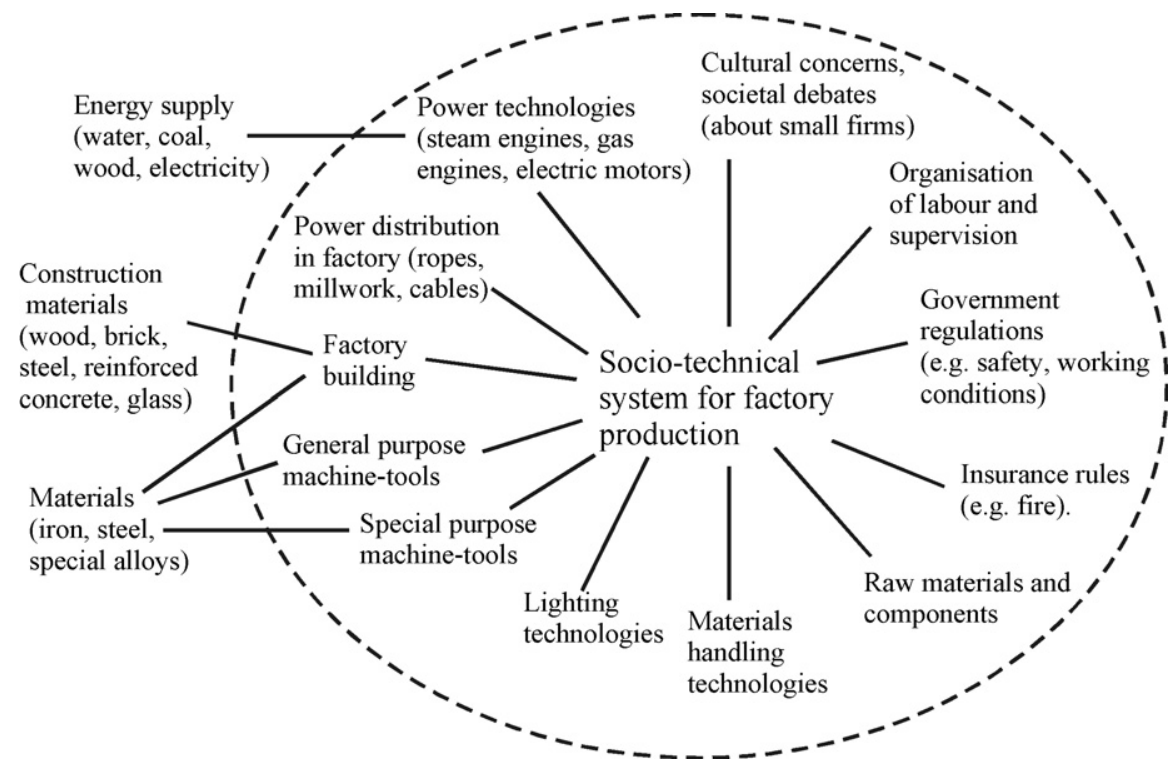

Fig. 11. Sociotechnical regime in factory production. 
diffused in sectors such as cigarette making, furniture, cloth, grain products, soap and canned foods. The canning industry pioneered combinations of machine tools and conveyor belts. Electricity also entered factories, first as electric light and as electric-powered fans to remove dust. But in the early 1890s, industries such as clothing, electrical machinery, printing and publishing began to use electric motors to power machine tools. By 1899, electric motors accounted for $5 \%$ of aggregate power in American industry.

In the first decade of the 20th century, industrial engineers became spokespersons for broader change. They developed new ideas about the use of space and positioning of machine tools. Flow, throughput and efficient factory layout became important guiding principles. Steel and reinforced concrete enabled the construction of larger buildings. And electric motors, which increased their share in aggregate power from 5 to $25 \%$ between 1899 and 1909, created opportunities to escape the direct-drive system and its inflexibilities. With unit-drive electric motors, machine tools could be placed more flexibly according to the sequence of work. This created opportunities for new factory layouts that made better use of floor space and minimised material flows between workstations.

The new opportunities were most actively explored in the automobile industry. Ford's innovation consisted of new combinations of existing elements. Special-purpose machine tools, division of labour, interchangeable parts, electric motors and the assembly line were reconfigured into a new production system. While early experiments occurred at the Highland Park factory (1913), the new form of mass production came into full realisation at the River Rouge plant (1920) with large, single-storey buildings that combined rational factory planning with modern production, power and construction technologies.

Several external landscape developments influenced this transition, e.g. the emergence of a national market, population growth, economic growth and rising purchasing power, the rise of engineers, electricity as pervasive technology, and the Efficiency Movement. While these landscape developments create opportunities and pressure, the main characteristic of this transition path was the interaction between multiple component innovations and the regime. The transition to mass production was not driven by one breakthrough innovation, but by sequences of multiple component innovations. The innovations were initially adopted to solve particular problems, but eventually enabled major changes in the basic architecture of factory production.
P5. If landscape pressure takes the form of 'disruptive change', a sequence of transition pathways is likely, beginning with transformation, then leading to reconfiguration, and possibly followed by substitution or de-alignment and re-alignment.

'Disruptive change' is a specific kind of landscape development. Because of its slow speed, actors initially perceive only moderate change. As pressure continues to build in a certain direction, landscape change gradually becomes more disruptive. This characteristic may lead to a particular sequence of transition pathways. ${ }^{13}$

Initially actors perceive moderate landscape change, which causes some regime problems. Regime actors address these problems with internal resources, changing the direction of activities and development trajectories. If problems are solved, the result is a transformation path (P1). If, however, landscape pressure increases and problems exacerbate, regime actors may become more willing to incorporate symbiotic niche-innovations and implement component changes. If these additions leave the regime architecture intact, this is still a transformation path (P1). But if these additions trigger architectural adjustments, the result is a reconfiguration path (P4). If problems are solved, regime actors will survive. Meanwhile, landscape pressures and regime problems also stimulate entrepreneurs and new firms to develop radical niche-innovations. If landscape pressure becomes more disruptive, previous regime improvements may appear insufficient. If regime problems grow worse, incumbent actors begin to lose faith. If a particular niche-innovation has been developed sufficiently, it may take advantage of this window of opportunity, resulting in technological substitution (P3). If niche-innovations are not yet sufficiently developed, the result will be de-alignment and re-alignment, with multiple niche-innovations blossoming and co-existing for a while, eventually followed by one option becoming dominant (P2).

This sequential pattern indicates that crossovers may occur between transition pathways. Climate change may in future decades become such a disruptive landscape change, triggering such a sequence of transition paths in transport and energy regimes.

\section{Discussion: transition pathways and agency}

Section 3 demonstrated that agency is always present in the MLP, because the three levels provide different

\footnotetext{
13 Smith et al. (2005, p. 1499) also address the issue of changes between transition paths. They do so in an explicitly normative way (seeing it as a task for governance), while we deal with it analytically.
} 
Table 3

Main actors and (inter)actions in transition pathways

\begin{tabular}{|c|c|c|c|}
\hline Transition pathways & Main actors & Type of (inter)actions & Key words \\
\hline 1. Transformation & $\begin{array}{l}\text { Regime actors and outside } \\
\text { groups (social movements) }\end{array}$ & $\begin{array}{l}\text { Outsiders voice criticism. Incumbent } \\
\text { actors adjust regime rules (goals, } \\
\text { guiding principles, search heuristics) }\end{array}$ & $\begin{array}{l}\text { Outside pressure, institutional power } \\
\text { struggles, negotiations, adjustment of } \\
\text { regime rules }\end{array}$ \\
\hline $\begin{array}{l}\text { 2. Technological } \\
\text { substitution }\end{array}$ & $\begin{array}{l}\text { Incumbent firms versus new } \\
\text { firms }\end{array}$ & $\begin{array}{l}\text { Newcomers develop novelties, which } \\
\text { compete with regime technologies }\end{array}$ & $\begin{array}{l}\text { Market competition and power } \\
\text { struggles between old and new firms }\end{array}$ \\
\hline 3. Reconfiguration & Regime actors and suppliers & $\begin{array}{l}\text { Regime actors adopt } \\
\text { component-innovations, developed } \\
\text { by new suppliers. Competition } \\
\text { between old and new suppliers }\end{array}$ & $\begin{array}{l}\text { Cumulative component changes, } \\
\text { because of economic and functional } \\
\text { reasons. Followed by new } \\
\text { combinations, changing } \\
\text { interpretations and new practices }\end{array}$ \\
\hline $\begin{array}{l}\text { 4. De-alignment and } \\
\text { re-alignment }\end{array}$ & New niche actors & $\begin{array}{l}\text { Changes in deep structures create } \\
\text { strong pressure on regime. } \\
\text { Incumbents lose faith and legitimacy. } \\
\text { Followed by emergence of multiple } \\
\text { novelties. New entrants compete for } \\
\text { resources, attention and legitimacy. } \\
\text { Eventually one novelty wins, leading } \\
\text { to restabilisation of regime }\end{array}$ & $\begin{array}{l}\text { Erosion and collapse, multiple } \\
\text { novelties, prolonged uncertainty and } \\
\text { changing interpretations, new winner } \\
\text { and restabilisation }\end{array}$ \\
\hline
\end{tabular}

degrees and kinds of structuration to local practices (Section 3). Still, we acknowledge that agency does not always come through strongly in stylised casestudies and figures. Why is this so? In this respect Poole and Van de Ven (1989) made a useful distinction, arguing that process theories should have two complementing components: global and local models:

"The global (macro, long-run) model depicts the overall course of development of an innovation and its influences, while the local (micro, short-run) model depicts the immediate action processes that create short-run developmental patterns. (...) A global model takes as its unit of analysis the overall trajectories, paths, phases, or stages in the development of an innovation, whereas a local model focuses on the micro ideas, decisions, actions or events of particular developmental episodes" (p. 643).

The MLP typically is a global model that maps the entire transition process. Such a global model tends to give less attention to actors. Yet, the MLP does allow the analyst to zoom in on actors: "Because the linkages between processes at different levels are made by actors in their cognitions and activities, the dynamics [in the MLP] are not mechanical, but socially constructed. (...) Transitions are contested and different groups struggle, negotiate, and form coalitions" (Geels, 2005b, p. 453). These 'local' dynamics can be shown in elaborate single case studies. This is difficult, however, for the transition pathways typology and the 1-page examples, which address aggregate patterns in long time periods ( $>50$ years). Nevertheless, Table 3 summarises the main actors and the main types of (inter)actions in the different pathways.

This incorporation of agency in transition pathways invites some further fundamental reflections on theory and agency. With its focus on interactions between niches, regimes and landscape, the MLP perspective provides narrative explanations. This does not imply storytelling or empiricism. The main point is that narrative explanations do not work with dependent and independent variables, but explain in terms of patterns that result from interactions. This is a specific type of theory, coined in the literature as process theory (Abbott, 2001; Pettigrew, 1997; Poole et al., 2000). Process theories explain outcomes as the result of temporal sequences of events, timing and conjunctures of event-chains. Situated groups make moves, undertake actions and react to each other. Processes are understood as sequences of events that are enacted by situated actors. Different foundational paradigms conceptualise agency in different ways. Four foundational conceptions are the following (Gioia and Pitre, 1990):

(1) Rational choice. Actors are self-interested, have objectives and preferences, and use cost-benefit calculations to select optimal choices. Change is understood as outcome of investments, price/performance improvements and market competition.

(2) Interpretation. Actors are interpretive, and use cognitive rules and schemas to make sense of the 
world. Interpretations of reality are constructed through collective sensemaking and social interactions. Change is understood as social construction of shared meaning and negotiations.

(3) Power. Actors and social groups have conflicting goals and interests. Change arises from conflicts, power struggles, contestations, lobbying, coalition building and bargaining.

(4) Deep structures. Actors share deep structures where fundamental categories and assumptions reside (e.g. symbolic sets, cultural repertoires. New cultural symbols and repertoires initially emerge as ideologies and struggles over legitimacy (Swidler, 1986). As they become more widely accepted, they gradually turn into deep structures and become taken-for-granted.

Many specific theories work within one of these fundamental paradigms. One disadvantage is reductionism, i.e. explanations that give undue emphasis to some type of agency, and that highlight some causal processes at the expense of other significant causes. A related disadvantage is that single paradigm theories provide constant-cause explanations, assuming that one causal factor operates constantly and explains emergence, decline and transformation. These two issues are not problematic for research questions and topics that are demarcated and short-term. For the topic of transitions, however, both issues are problematic. Detailed case studies have shown that most transitions involve multiple types of agency and causal processes that may alternate. This implies that transition theory needs to accomodate various types of agency.

We propose that a rule-based model of action, on which the MLP is based, incorporates different ways of conceptualising agency. Various types of rule-based action (rule-following, using, creation and alteration) can be related to the four foundational paradigms: (1) rational-action involves conscious attempts to determine the best action among possible choices. This entails rule-using, because cost-benefit calculations are only possible when formal, normative and cognitive rules provide a stable frame for calculation (Hodgson, 1997; Callon, 1998). (2) Interpretations and sensemaking involve rule-using (e.g. cognitive frames), rule-creation and rule-alteration, but analysis often focuses on the latter two. Interpretative action is best profiled as negotiated change of shared meanings. (3) Traditional power approaches focus on formal rule-alterations, e.g. through lobbying and institutional entrepreneurship from collective actors, such as professional societies, industry associations, and social movements. ${ }^{14}$ (4) Deep structures are usually reproduced through routine action that consists of rule-following.

So, a rule-based model of action is multi-dimensional. Following Giddens (1984), we understand rules as structures, which are recursively reproduced (used, changed) by actors. This agency-structure dynamic, which is also crucial in the MLP, leaves space for different kinds of action. Hence, detailed multi-level case studies show mixes of rational, interpretative, power based and routine actions. These forms of agency are simultaneously present, either contributing to change, stability or forming a taken-for-granted backdrop. Their contributions to transitions can vary depending on the unfolding pathway. Transitions can be induced through rational action, as well as through changing interpretations or power struggles. This was visible in Table 3, where contributions of agency dimensions varied for the different transition paths. So while the multi-level perspective provides an overall 'global' framing for all transition pathways, the narrative event-sequences are always enacted and leave space for different 'local' subplots.

\section{Conclusions}

In response to constructive criticisms this article provided conceptual refinements in the multi-level perspective on transitions. The relations between the three structural levels and agency have been clarified. The presumed niche-driven bias has been overcome by developing a more differentiated typology of transition paths, based on differences in timing and nature of multilevel interactions. Also specific types of agency and (inter)actions have been identified for the different pathways, suggesting a local model to complement the structuralist global model. These issues have been situated in fundamental debates about paradigmatic agency assumptions and types of theory. The article only touched upon these debates, scratching the surface of interesting topics that deserve more attention in the future.

One qualification is that pathways are not deterministic. Although the examples described successful transitions, the sequences of events are not automatic. There is no guarantee that a new sociotechnical regime will be established. Another qualification is that the pathways are ideal types. Their application to empirical cases

\footnotetext{
${ }^{14}$ Recent approaches see power as a multi-faceted phenomenon that is also implicated in markets and interpretation (through influences on agenda setting and problem framing). Such multi-faceted approaches allow crossovers to the rational and interpretive paradigms.
} 
requires care and balancing of arguments. Transition pathways need not always occur in their pure form, as our discussion of examples showed. The example of hygienic transformation had some aspects of substitution, because sewer systems replaced cesspools. And the example of horse-drawn carriages and automobiles was a mix of de-alignment and re-alignment and two subsequent technological substitutions. Despite these qualifications, we maintain that pathways have a recognisable internal logic, constituted by different combinations of dynamic mechanisms.

\section{Acknowledgements}

Several people provided generous comments on previous versions of this article. We particularly thank Frans Berkhout, Jeroen van den Berg, John Grin, Ruth McNally, Alessandro Nuvolari, Rob Raven, Jan Rotmans, Fred Steward, Deborah Tappi, Geert Verbong and two anonymous referees. We gratefully acknowledge financial and other support from the Dutch Knowledge Network on System Innovation (KSI). We are fortunate to evolve together with many scholars who contribute to this network.

\section{References}

Abbott, A., 2001. Time Matters: On Theory and Method. University of Chicago Press, Chicago, IL.

Berkhout, F., Smith, A., Stirling, A., 2004. Socio-technological regimes and transition contexts. In: Elzen, B., Geels, F.W., Green, K. (Eds.), System Innovation and the Transition to Sustainability: Theory, Evidence and Policy. Edward Elgar, Cheltenham, pp. 48-75.

Bijker, W.E., 1995. Of Bicycles, Bakelites and Bulbs: Towards a Theory of Sociotechnical Change. The MIT Press, Cambridge, MA, London, England.

Callon, M. (Ed.), 1998. The Laws of the Market. Blackwell, Oxford.

Christensen, C., 1997. The Innovator's Dilemma: When New Technologies Cause Great Firms to Fail. Harvard Business School Press, Boston, MA.

DiMaggio, P.J., Powell, W.W., 1983. The iron cage revisited: institutional isomorphism and collective rationality in organizational fields. American Sociological Review 48, 147-160.

Elzen, B., Geels, F.W., Green, K. (Eds.), 2004. System Innovation and the Transition to Sustainability: Theory, Evidence and Policy. Edward Elgar, Cheltenham.

Freeman, C., Perez, C., 1988. Structural crisis of adjustment, business cycles and investment behaviour. In: Dosi, G., Freeman, C., Nelson, R., Silverberg, G., Soete, L. (Eds.), Technical Change and Economic Theory. Pinter, London, pp. 38-66.

Garud, R., Rappa, M.A., 1994. A socio-cognitive model of technology evolution: the case of cochlear implants. Organization Science 5 (3), 344-362.

Geels, F.W., 2002. Technological transitions as evolutionary reconfiguration processes: a multi-level perspective and a case-study. Research Policy 31 (8/9), 1257-1274.
Geels, F.W., 2005a. Technological Transitions and System Innovations: A Co-Evolutionary and Socio-Technical Analysis. Edward Elgar, Cheltenham.

Geels, F.W., 2005b. The dynamics of transitions in socio-technical systems: a multi-level analysis of the transition pathway from horse-drawn carriages to automobiles (1860-1930). Technology Analysis \& Strategic Management 17 (4), 445-476.

Geels, F.W., 2006a. The hygienic transition from cesspools to sewer systems (1840-1930): the dynamics of regime transformation. Research Policy 35 (7), 1069-1082.

Geels, F.W., 2006b. Major system change through stepwise reconfiguration: a multi-level analysis of the transformation of American factory production (1850-1930). Technology in Society 28 (4), $445-476$.

Giddens, A., 1984. The Constitution of Society: Outline of the Theory of Structuration. University of California Press, Berkeley.

Gioia, D.A., Pitre, E., 1990. Multiparadigm perspectives on theory building. Academy of Management Review 15, 584-602.

Henderson, R.M., Clark, K.B., 1990. Architectural innovation: the reconfiguration of existing product technologies and the failure of established firms. Administrative Science Quarterly 35, 9-30.

Hodgson, G.F., 1997. The ubiquity of habits and rules. Cambridge Journal of Economics 21, 663-684.

Hoogma, R., Kemp, R., Schot, J., Truffer, B., 2002. Experimenting for Sustainable Transport: The Approach of Strategic Niche Management. Spon Press, London and New York.

Kemp, R., Schot, J., Hoogma, R., 1998. Regime shifts to sustainability through processes of niche formation: the approach of strategic niche management. Technology Analysis and Strategic Management 10, 175-196.

Levinthal, D.A., 1998. The slow pace of rapid technological change: gradualism and punctuation in technological change. Industrial and Corporate Change 7 (2), 217-247.

Mumford, L., 1967. The Myth of the Machine: Technics and Human Development. Hartcourt, Brace \& World, New York.

Nelson, R.R., Winter, S.G., 1982. An Evolutionary Theory of Economic Change. Belknap Press, Cambridge, MA.

Perez, C., 2002. Technological Revolutions and Financial Capital: The Dynamics of Bubbles and Golden Ages. Edward Elgar, Cheltenham.

Pettigrew, A.M., 1997. What is a processual analysis. Scandinavian Journal of Management 13 (4), 337-348.

Poole, M.S., Van de Ven, A.H., 1989. Towards a general theory of innovation processes. In: Van de Ven, A.H., Angle, H.L., Poole, M.S. (Eds.), Research on the Management of Innovation: The Minnesota Studies. Harper \& Row Publishers, New York, pp. 637662.

Poole, M.S., Van de Ven, A.H., Dooley, K., Holmes, M.E., 2000. Organizational Change and Innovation Processes: Theory and Methods for Research. Oxford University Press, New York.

Raven, R.P.J.M., 2005. Strategic Niche Management for Biomass. Eindhoven University, The Netherlands.

Rip, A., 1992. A quasi-evolutionary model of technological development and a cognitive approach to technology policy. Rivista di Studi Epistemologici e Sociali Sulla Scienza e la Tecnologia 2, 69-103.

Rip, A., Kemp, R., 1998. Technological change. In: Rayner, S., Malone, E.L. (Eds.), Human Choice and Climate Change. Battelle Press, Columbus, OH, pp. 327-399.

Rogers, E., 1996. The Diffusion of Innovations. Free Press, New York.

Rosenberg, N., 1982. Inside the Black Box: Technology and Economics. Cambridge University Press, Cambridge, MA. 
Rotmans, J., Kemp, R., Van Asselt, M., 2001. More evolution than revolution: transition management in public policy. Foresight 3 (1), 15-31.

Sahal, D., 1985. Technological guideposts and innovation avenues. Research Policy 14, 61-82.

Schot, J.W., 1992. The policy relevance of the quasi-evolutionary model: the case of stimulating clean technologies. In: Coombs, R., Saviotti, P., Walsh, V. (Eds.), Technological Change and Company Strategies: Economic and Sociological Perspectives. Academic Press, London, pp. 185-200.

Schot, J.W., 1998. The usefulness of evolutionary models for explaining innovation. The case of the Netherlands in the nineteenth century. History of Technology 14, 173-200.

Scott, W.R., 1995. Institutions and Organizations. Sage Publications, Thousand Oaks, CA.

Smith, A., Stirling, A., Berkhout, F., 2005. The governance of sustainable socio-technical transitions. Research Policy 34, 1491-1510.

Smith, A., 2006. Green niches in sustainable development: the case of organic food in the United Kingdom. Environment and Planning C: Government and Policy 24, 439-458.
Suarez, F.F., Oliva, R., 2005. Environmental change and organizational transformation. Industrial and Corporate Change 14 (6), 1017-1041.

Swidler, A., 1986. Culture in action: symbols and strategies. American Sociological Review 51 (2), 273-286.

Tushman, M., Anderson, P., 1986. Technological discontinuities and organization environments. Administrative Science Quarterly 31, 465-493.

Unruh, G.C., 2000. Understanding carbon lock-in. Energy Policy 28, 817-830.

Van de Poel, I., 2000. On the role of outsiders in technical development. Technology Analysis \& Strategic Management 12 (3), 383397.

Van de Poel, I., 2003. The transformation of technological regimes. Research Policy 32, 49-68.

Van Driel, H., Schot, J., 2005. Radical innovation as a multi-level process: introducing floating grain elevators in the port of Rotterdam. Technology and Culture 46 (1), 51-76. 